\title{
OJOS VERDES: IMAGINARIOS FEMENINOS Y NARRATIVAS TRANSTEXTUALES
}

\author{
GREEN EYES: FEMININE IMAGINARIES \\ AND TRANSTEXTUAL NARRATIVES
}

Alberto Martos García

Universidad de Extremadura. Badajoz, España

albertomg@unex.es

Eloy Martos Núñez

Universidad de Extremadura. Badajoz, España

emartos@unex.es

\begin{abstract}
Resumen: Se comparan los patrones narratológicos de un mismo mito base, la ninfa de las agua de ojos cautivadores, a través de tres hitos significativos. En primer lugar, el origen del mito en Grecia a través de Medusa y otras historias conexas. En segundo término, la leyenda de Bécquer Ojos verdes que literaturiza un mito de damas de agua muy común en la península ibérica. Y en tercer lugar, la versión en clave de novela negra de Lorenzo Silva. En los tres casos, más que con un canon de belleza, la alusión a los ojos verdes se asocia con una experiencia iniciática, cuya relación con el simbolismo del agua y sus imaginarios femeninos se mantiene. Se comparan estos hitos para subrayar sus afinidades y diferencias y se propone una apertura hermenéutica susceptible de integrar las nuevas lecturas. En este sentido, se preconizan lecturas alternativas que pongan en valor el discurso de la naturaleza y de la mujer.
\end{abstract}

Palabras clave: Mito, ojos verdes, damas de agua, imaginarios femeninos, hermenéutica.

\begin{abstract}
Narratological patterns of a same myth are compared base, the nymph of the water of captivating eyes, through three significant milestones. First, the origin of the myth in Greece through Medusa and other related stories. Secondly, the legend of Bécquer Green eyes that mentioned a myth of ladies of common water in the Iberian peninsula. And thirdly, the black novel of Lorenzo Silva key version. In all three cases, most with a canon of beauty, the allusion to the green eyes relates an initiatory experience, whose relationship with the symbolism of water and their imaginary female
\end{abstract}


is maintained. These milestones are compared to highlight their affinities and differences and intends to open were likely to integrate the new readings. In this sense, is advocated by reading alternatives that put to value nature and women's speech.

Keywords: Myth, green eyes, waters spirits, feminine imaginaries, hermeneutic.

Recibido: 06.03.2014. Aceptado: 31.07.2014.

\section{Introducción: El mito como hipotexto literario}

$\mathrm{L}$ A TRANSTEXTUALIDAD es una noción desarrollada por Genette (1989) a Através de diversas subcategorías, en el marco de su conocida visión de la escritura como "palimpsesto". Para éste existirían varias modalidades, tales como la intertextualidad, la paratextualidad, la metatextualidad o la hipertextualidad. Nos hallamos, pues, ante la capacidad dinámica propia de la cultura entendida como texto (Lotman, 1979), susceptible de renovar sus códigos y sus textos, aunque esto nunca sucede ex nihilo sino a través de la reescritura de tradiciones preexistentes, de ahí la relación entre palimpsesto e hipotexto. La propiedad de regeneración de los imaginarios culturales es similar a lo que Scavino y Buzón (2008) denominan poética de la polifonía, pues los mecanismos de traducción y transtextualidad que ellos describen, a propósito de Borges y La Casa de Asterión, bien podrían extrapolarse al caso que nos ocupa.

También debe atenderse al juego de textos (Bajtin, 1974) que entran en cruce, diálogo o contraste con otros. Ciertamente, no siempre es fácil establecer un texto-fuente, un hipotexto puro que podamos cotejar, elemento a elemento, con su hipertexto, porque el espacio dialógico permite multitud de movimientos, desde la imitación becqueriana del mito de los ojos cautivadores al desvío de la versión de Lorenzo Silva. Pero en las dos versiones aludidas, el narrador se autopresenta para ofrecernos una historia maravillosa, si bien no con el viejo ardid cervantino del manuscrito encontrado, sino con un testimonio que "a él le han contado", en palabras de Silva. En todo caso, el denominador común de las tres versiones es presentar una mujer hermosa a la par que terrorífica. El hipotexto, en cambio, es un discurso subyacente con el cual el texto guarda una relación de dependencia o filiación. Así, la novela de caballerías es un hipotexto activo en el Quijote. El problema de los hipotextos es su visibilidad, que varía según muchos 
factores: así, el receptor infantil puede no conocer el hipotexto mitológico que subyace a una historia como Shreck, o bien puede conocerlo solo parcialmente, es el caso de versiones cinematográficas como las de Disney. El resultado puede ser que ignore la estructura paródica que pueda tener un texto, en relación precisamente a su hipotexto: leer Caperucita en Manhattan de Carmen Martín Gaite o innovar sobre el cuento requiere, claro, conocer la "versión canónica".

\section{Ojos verdes y Medusa: Momento inicial, la narrativa mítica}

Es sabido que Medusa es un monstruo ctónico femenino, que convertía en piedra a quienes miraba, y que termina convirtiéndose en una máscara de poder que héroes y dioses usaban como amuleto (gorgoneion). No revisaremos sus fuentes y simbolismos, salvo en lo relativo al aspecto en cuestión: los ojos, la visibilidad, y su reverso la invisibilidad, pues no en vano tenemos el mito próximo de Britomartis, diosa cretense de las montañas, que a su vez se relaciona con Afaya, en griego Apaía, con la raíz faino-, "aparecer", "resplandecer", y alfa privativa. El propio Pausanias (Descripción de Grecia, II.30.3) cuenta que, perseguida por Minos, se moldeó a sí misma en forma de red para pescar y, recogida por un pescador, se hizo invisible, es decir, sin luz. Las concomitancias son evidentes: la capacidad de mostrarse o de desaparecer, su vinculación a la naturaleza y a las aguas, la ambivalente relación de cortejo con un perseguidor del otro sexo, la ninfa que es cambiada en numen invisible por mediación de una diosa...

Así que los ojos son el nexo que unen a Medusa con la cultura del agua, pues no olvidemos que en el origen etimológico de la palabra dragón, genio acuático por excelencia, está el verbo drakomai, que significa mirar profundamente. Y es que las leyendas de ninfas son unos auténticos palimpsestos culturales pues, siguiendo a Calasso (2004), es fácil colegir cómo las ninfas se transmutaron en hadas en el imaginario europeo postclásico, y cómo las ninfas o hadas del folclore han sido, a su vez, el troquel sobre el cual los tópicos literarios renacentistas han creado sus propias prosopografías, baste citar las ninfas de la Égloga III de Garcilaso y todo el tópico del locus amoenus: "Peinando sus cabellos de oro fino / una ninfa del agua do moraba / la cabeza sacó, y el prado ameno /vido de flores y de sombra lleno". 
En cambio, en el folclore el lugar donde mora el genius loci protegiendo un tesoro es, a menudo, el mismo oros o monte agreste de los griegos, es decir, un lugar de caos y de peligro, y no un edénico locus amoenus. De modo que estas leyendas distan de la visión bucólica literaria, por ejemplo, con respecto a la actividad dionisíaca de las ninfas primitivas (Calasso, 2004), quienes bailan, cantan o son poseídas por un delirio que las lleva incluso a despedazar a quien profane el lugar sagrado. Paralelamente, Medusa es presentada como un monstruo grotesco, con atributos tales como el pelo a modo de serpiente, los ojos centelleantes o la lengua fuera, es decir, las formas ambivalentes, terribles o grotescas de representación de la Diosa Madre. De ahí, su uso ancestral no es solo como amuleto mágico sino como espantajo para asustar a los niños, ya en la misma Grecia, a fin de que no se asomaran a pozos, charcas o simas. Conque el aspecto terrible o siniestro es el nexo entre estas fabulaciones: el mito de Medusa, en realidad explica la cratofanía o apoteosis de la naturaleza (asumiendo el sincretismo ninfa-dragón-fuente, Calasso, 2004), es decir, la manifestación más terrible del numen, su superabundancia o fuerza majestuosa (Otto, 1980). Convergiendo con esta misma interpretación, la Ecocrítica (Flys, Marrero y Barella, 2010) ha subrayado la afinidad entre los discursos feminista y ecologista en cuanto a hacer visible una voz silenciada y sojuzgada -la de la Naturaleza y la de la mujer-, de ahí que irrumpa, en efecto, demonizada igual que Medea.

En resumen, en el patrón de Medusa se amalgaman diversas tradiciones, y su prosopografía es heredera de tales simbolismos: los pueblos autóctonos son demonizados o adoptan rasgos monstruosos, lo cual además connota otra dimensión presente en la mitología. La monstruosidad va ligada a la fuerza de la magia, de modo que Medusa es una gran hechicera y tiene que ser por tanto monstruosa. La vinculación con las serpientes y otros rasgos (la gran boca, los ojos centelleantes, la barba o la lengua sacada fuera) alude a esta fisonomía teriomórfica y grotesca de lo sagrado, al igual que con la Hidra, Equidna y otros monstruos. Rasgos similares están también en los atributos de Atenea, la de ojos brillantes de lechuza ( $\gamma \lambda \alpha v \kappa \tilde{\omega} \varpi \iota \varsigma)$, como la llama Homero, lo cual la relaciona con una arcaica diosa pájaro, o "reina de la noche", tal vez, Lilit, la bruja-demonio que hechiza a los hombres en el folclore judío.

Además, la decapitación de Medusa ha dado pie a una reinterpretación 
que pone el énfasis en que es una máscara apotropaica ligada a ciertos cultos y usos mágicos (gorgoneion). Dicho de otro modo, parece ante todo una cabeza sin cuerpo, o incluso una máscara con rasgos muy expresivos (la orgé theoy o cólera divina de que habla Otto (1980), como formas de expresión de este genius loci de las aguas profundas. Por tanto, cuando en Ojos verdes, Bécquer hace que el protagonista vislumbre unos ojos en el agua, y no un cuerpo, está influenciado por este mismo perfil mitográfico.

Por otra parte, sabemos que a los pozos se lanzaban ofrendas personales para solicitar curaciones, oráculos y favores de todo tipo, incluyendo maldiciones. Estas solicitaciones eran contestadas a menudo por voces del agua (oráculos) o fugaces apariciones de la señora del agua, de aspecto ambivalente, unas veces más feéricas (Vax, 1960) o "amables" y otras más siniestras. Lo que sí sabemos, y eso pertenece al orden mágico-soberano de Dumézil (1977), es la importancia de ciertos tabúes: no sorprender (profanar) el baño de la ninfa, no mirar atrás, no mirar de frente... Por tanto, el héroe que triunfa, como Perseo, es quien entiende la situación y sabe actuar en consecuencia.

Mecanismos como la transpersonificación o el desdoblamiento explican esta labilidad escenográfica, donde aparecen enfatizadas unas veces la misma fuente o paisaje, otras la serpiente o el genio local, y otras la dama de agua, ninfa o encantada. También ocurre que se amalgamen todas estas representaciones, por ejemplo, Medusa con su cabello formado por serpientes. Sea como sea, la narración mítica nos viene a hablar de un personaje que se corresponde con los rasgos de las damas encantadas, ancladas a un lugar por una especie de maleficio, y que otorgan dones o desgracias según los casos. Por todo ello, ha propuesto H.J. Harrison (1903) que en la base del mito de Medusa lo que tenemos es una cabeza o máscara de poder con grandes ojos, al igual que ya aparece en las representaciones neolíticas de la Gran Diosa (Gimbutas, 1974), donde ésta es representada a menudo como una lechuza con grandes ojos, atributo que luego heredará Atenea, y con el que será reproducida en monedas.

Los ojos pintados sobre los barcos griegos (ofptalmoi) obedecen a esta misma lógica de incorporar una deidad protectora que alejase los malos espíritus. Los ojos del navío eran tanto como los ojos de la deidad, y su función religiosa era tal que la proa donde se ponía la máscara era un lugar sagrado, en el cual se han encontrado cráteras o copas para abluciones ritua- 
les. Así pues, los ojos grandes y centelleantes son un símbolo denominado ojos divinos por Gimbutas (1996), que aparecen también en la lechuza de Atenea, y la Gorgona Medusa encubre la naturaleza terrorífica del numen (Otto 1980).

\section{Ojos verdes de Bécquer y La ondina del lago azul de Gómez de Avellaneda: segundo momento, narrativa romántica}

Hay diferentes aproximaciones acerca de los préstamos y posibles trasvases entre el cuento de Gómez de Avellaneda y las leyendas de Bécquer (Gulsoy, 1967), tema que, en todo caso, se puede iluminar si valoramos que, sean cuales sean las influencias, ambas son literaturización de versiones orales de leyendas. Éste es el primer punto o "estación" de la recepción del texto, el hecho de que partan de tradiciones folclóricas reconocibles, da sentido, precisamente por esto, a las posteriores versiones parafolclóricas, literarias o periodísticas. Lo cierto es que los referentes indudables son las damas de agua o lamias del norte peninsular español, de ahí su afinidad con otras muchas historias de xanas o lavanderas de Asturias (Cabal, 1972), o también de las lamias, lamiñas o lamiñaku del País Vasco, o de las gojes o dones d'aigua de Cataluña, etc. Es sabido que Gómez de Avellaneda publicó en 1860 La ondina del lago azul con el subtítulo Recuerdo de mi última excursión por los Pirineos, haciendo alusión a las fuentes orales (el guía Lorenzo) que le transmitieron la base de la historia. Por su parte, Ayala (2006) subrayó la diversidad de estratos y tradiciones que subyacen a esta obra, y debemos a Charques Gámez (2013) un desglose de lo popular y lo culto en estas recreaciones tradicionales de la autora. En realidad, la propia narración tiene diversas perspectivas hermenéuticas, desde la pura ensoñación romántica de Gabriel a la interpretación evemerista de Lorenzo, al descubrirse que hay una joven frívola que vivía en el entorno y que es la presunta causante de la desgracia del joven.

Cabe concluir que, sobre este sustrato de damas de agua y de encantamientos, los dos autores arman sus versiones, que literaturizan el mito en direcciones parecidas, aunque con matices singulares, por ejemplo, la "maldad" o perfidia del genio acuático es dibujada con trazos más gruesos o finos según cada autor, o la visión de la otredad y de la identidad 
femenina. Lo cierto es que en el folclore peninsular hay diversas leyendas relativas, como por ejemplo la de la Laguna o Torca de la Gitana en la sierra de Cuenca, que explican el verdor que adquieren periódicamente las aguas por el suicidio de la novia. En efecto, las hoyas y torcas son un capricho geológico donde el agua adopta diferentes tonos verdosos, de ahí que tanto el vulgo como Bécquer (rima XII) atribuyeran el color verde a los ojos de las náyades.

Sin duda el mito de Medusa y de otros genios acuáticos es el hipotexto que subyace a la leyenda becqueriana Ojos verdes, que va imitando y literaturizando tales esquemas folclóricos. ¿Cómo? Haciendo patentes ciertas marcas literarias, como los juegos de la enunciación, el hacer explícito el narrador y su punto de vista, o el añadir el psicologismo y la expresión de estados de ánimo, ajenos al mito original pero en sintonía total con la cosmovisión romántica: así, la soledad como sentimiento metafísico y de aislamiento del yo, proyectado en el paisaje, y el conocido tópico de la mujer fatal, que va impregnando el texto.

Al igual que los tópicos pastoriles del s. XVI son una invención de las élites, al margen de las clases populares que vivían el paisaje y no lo intelectualizaban (Berque, 2009), en este caso la imaginación creadora, como facultad que caracteriza la poética romántica, es la que usa el paisaje como espejo del alma; de ahí la búsqueda de lo sobrenatural o de la divinidad en la naturaleza, pero para otorgarle una caracterización que tiene más que ver con la languidez de las ondinas germánicas que con la fuerza y determinación de las ninfas latinas, que actúan sin miramientos. Es el caso de la xana o dama de agua asturiana Caricea, que como espíritu maligno se deja estrechar por el romano Carisio pero para arrastrarlo a la profundidad del lago Noceda.

Esta misma ambivalencia jalona muchas otras historias de encantadas, reinas moras, xanas y toda una gran variedad de genios acuáticos, que son en realidad divinidades tópicas, es decir, se comportan como genios del lugar, protegiendo ocultos tesoros y viviendo en palacios encantados, y que someten a pruebas a los intrusos antes de otorgarles un don o un castigo. Bécquer solamente toma de este patrón hidromítico lo que le interesa, para expresar sentimientos parecidos a los de Un rayo de luna, la mujer inasible capaz de colmar el vacío sentimental del poeta. Por ello, adopta el motivo de la caza y del corzo sin relacionarlo con la Diosa Blanca (Graves, 1983 
[1948]), sino más bien como preparación del descubrimiento de la Fuente de los Álamos, en el Moncayo. Sin embargo, la relación entre su personaje Fernando y la dama del agua es punto por punto equiparable a la fascinación que ejerce Calipso sobre Ulises, reteniéndole en la cueva en un estado permanente de trance extático.

En realidad, se puede decir que Bécquer vuelca en diversas leyendas (Un rayo de luna, La corza blanca, El gnomo...) una misma hierofanía: la Naturaleza se revela a través de sus genios en toda su pureza y grandiosidad, aunque ello lleve a la perdición a sus personajes. Por eso, estos escenarios se comportan igual que el antro o cueva iniciática de Calipso, pero ya el fin no es la consecución de ese tesoro o don, pues el propio poeta es consciente de que tales figuras son apenas ilusiones o espejismos del alma. Nótese que en el folclore narrativo hay multitud de apariciones "brillantes" que surgen en el campo o se reflejan en el agua, pero el alma romántica tampoco puede entenderla de la forma simple en que lo entiende la superstición campesina, pues está desgarrada siempre entre el mundo de la racionalidad y su continua desazón. A este respecto, Caparrós Esperante (1991: 365) subraya que hilo de luz es una expresión recurrente en Bécquer, que aparece también en esta leyenda ("Sus cabellos eran como el oro; sus pestañas brillaban como hilos de luz") y lo conecta con este simbolismo.

El final de la historia es ilustrativo de este callejón sin salida: una vez que Fernando ha perdido pie y caído al agua, solo se oye un rumor sordo y lúgubre, y el narrador apostilla: “...las aguas saltaron en chispas de luz y se cerraron sobre su cuerpo, y sus círculos de plata fueron ensanchándose, ensanchándose hasta expirar en las orillas". Por tanto, es una muerte intransitiva, que no da paso a otra cosa, a diferencia de los mitos de redención propios de los pozos celtas o de los oráculos griegos, que eran lugares de sanación y para obtener respuestas -buenas o malas- a las demandas del visitante. Ni siquiera podemos decir que la dama del agua se comporte como una lamia depredadora, a pesar de que lo aborde en la ribera de la fuente, porque toda la "enfermedad de espíritu" ya la trae el propio Fernando.

Así que su seducción, en forma de los diálogos que entabla con él, es poco más que una apoteosis retórica del lugar y de los misterios que impactan en el alma de Fernando. Porque es él quien se siente llamado por este lugar singular, quien es atraído hacia el borde del abismo, comportándose 
en realidad como un suicida, no ya en esta secuencia final sino desde el momento en que decide romper con todo para sumergirse en el encanto subyugante del sitio, pese a las admoniciones del montero y a las señales de peligro que se van colocando a lo largo de la leyenda. Se puede decir que Fernando fantasea despierto, y con ello escapa de una vida que no le satisface, y experimenta delirios o sensaciones sinestésicas muy fuertes, tal como la leyenda describe; llega incluso a desarrollar emociones y conductas adictivas, posponiendo sus obligaciones habituales. Como Ulises, Fernando se sumerge en este mundo anestesiante que le evita el dolor y el choque con la realidad, y tal vez ello explique el final: él no busca otra salida, no quiere retornar a la realidad, como los héroes míticos. Por eso conserva el patrón iniciático del mito, pero podado, reducido a su primera parte, al cruce del umbral y al encuentro con la diosa, sin explorar otras decisiones o itinerarios posibles.

\section{Ojos verdes de Lorenzo Silva: Momento tercero, la deconstrucción del mito en la novela negra}

Si el texto becqueriano Ojos verdes imita el patrón mítico, aunque sesgándolo hacia la cosmovisión romántica, la versión del escritor español Lorenzo Silva es en realidad una réplica en clave posmoderna, una novela negra en miniatura, donde el genio que pone a prueba y que tiene ojos verdes es un hombre, y el visitante una mujer, una ejecutiva de éxito en el contexto de Madrid, por más señas. La propia transmutación revela ya el grado de ironía o distanciamiento del mito de origen. La relación, pues, es de transformación, en el sentido que R. Graves (1983 [1948]) da al concepto de iconotropismo: los elementos de la historia persisten, pero son distorsionados o cambiados de lugar. La víctima es ahora una mujer de éxito, y el depredador de "ojos verdes" es un hombre, en un claro escorzo hacia la perspectiva de género. En el inicio del cuento, se parafrasea la prosopografía de Medusa adaptada a esta ejecutiva:

Dicen que era la tía más brillante que jamás pisó la moqueta de esta firma, líder en banca de inversiones. En cierto modo, estaba predestinada. Hija de familia adinerada, se había formado en el Liceo Francés hasta los catorce años y en un selecto colegio británico durante su adolescen- 
cia... cuando llegó aquí, a los veintitrés años, era una bestia perfectamente pentalingüe dispuesta a comerse el mundo y con los dientes lo bastante fuertes y afilados como para triturarlo entre sus mandíbulas. Y según afirma la leyenda, encima era muy atractiva, o como recuerda mi jefe, con la mirada suspendida en el techo, guapa hasta doler, oye, guapa hasta obligarte a pedir perdón por estar mirándola (Silva, 2007: 17).

$\mathrm{Al}$ igual que ocurre con el Fernando becqueriano, tenemos al principio el dibujo de un personaje triunfador, una mujer que es descrita además como distante y reservada, pero que revela un profundo vacío en su vida cuando, de repente, y como sucede con todas las llamadas iniciáticas, simplemente se encuentra en un tren de cercanías con la mirada de un hombre enigmático. Más que enamoramiento cabe hablar en verdad de "aojamiento", en el sentido folclórico de comunicar con los ojos, de esa mirada penetrante del dragón, basilisco o Medusa, que petrifica o paraliza. Le sigue hasta Getafe y allí, al bajarse, experimenta la sensación de extravío de sí misma más radical:

Ella se quedó sin saber qué hacer, con una desazón en el alma como nunca había sentido. Las puertas se cerraron y continuó aturdida hasta la estación siguiente, Getafe Central, donde se bajó. Salió a la calle a buscar un poco de aire. Tampoco había estado nunca en aquella ciudad... (Silva, 2007: 17).

Como el Fernando becqueriano, nuestra ejecutiva "pija” comienza a sufrir una quiebra y un desorden de su vida rutinaria ("corría como una loca por la estación”), que a la vez es compatible con la lucidez extraordinaria de la persona que sabe que va hacia su perdición y la acepta: sigue al hombre, lo aborda y se va con él a un piso modesto, donde, siempre impasible, le dice de forma contundente: "Si tú tampoco tienes miedo, ven conmigo. Te mereces lo que te vas a encontrar”. El desenlace es propio de la más escabrosa novela negra, pues aparecen los dos degollados. Silva sugiere algunas claves explicativas, y nos enteramos entonces de que el hombre era un recluso condenado por drogas, y de que la policía barajaba la hipótesis del ajuste de cuentas. El final es genial, pues supone abrir todas las interrogantes:

No quiero ir a la hemeroteca a mirar los periódicos. Tampoco los he 
buscado nunca en Internet. Me da miedo ver sus caras, que dicen que ilustraron la noticia en su día. No quiero ver la de ella, pero, sobre todo, no quiero ver esos ojos verdes. También yo viajo sola en tren, y siento, conforme pasan los días, que algo me falta (Silva, 2007: 30).

La inversión del mito no solo pasa por alterar los personajes principales, lo original es seguir enhebrando los elementos esenciales del mito, porque los "ojos verdes" que nos hechicen pueden venir de cualquiera. De hecho, en el caso de las Nix o nixe -el término más usual con que los hermanos Grimm se refieren a las ondinas- se las describe como una entidad "cambia-aspecto" (shapeshifting) y, en efecto, en las leyendas tenemos todo tipo de fisonomías: mujeres serpientes, como Melusina, Reinas Moras de aspecto esplendoroso, damas de agua de aspecto brillante o lamias siniestras... En suma, no te fíes de las apariencias, parece decirnos el autor, en el mismo tono de las fantasmagorías románticas.

El mito ancestral que venimos manejando explica que, bajo el símbolo de la Serpiente Antigua en sus múltiples representaciones, aparezca la prosopografía de un genio vinculado a las aguas que manifiesta los poderes de la Naturaleza en cada lugar, de ahí su propensión a aparecer como divinidad local. Ciertamente, esta deidad proteica, la Diosa Madre, se ramifica luego en nereidas, ondinas, ninfas y múltiples avatares, que se denominan genéricamente como damas de agua o encantadas. Pero, a la vista del texto de Lorenzo Silva, cabría preguntarse ¿dónde está, en este Madrid de asfalto, la cultura del agua, el lugar agreste que ampara las fuentes, lagos o pozos de las viejas historias...? Nada más fácil: en realidad, el propio entramado de Madrid, las calles son los ríos de piedra, y el mismo Ramón Gómez de la Serna en Nostalgias de Madrid escribe un sugerente artículo, Faroles con fuente, donde enmadeja agua y luz. Porque, si bien el agua parece oculta, como en las aguas subterráneas, en realidad es en este fluir incesante de personas de la ciudad posmoderna donde puede surgir un episodio de revelación y éxtasis: "los ojos verdes".

Lo que ocurra después es siempre enigmático, lo hemos comprobado en Bécquer, y se puede interpretar de un modo más o menos siniestro. Conforme a la apertura de significados propia de la escritura literaria, tal vez sea una experiencia de la desolación y la marginalidad, según se infiere del texto de Lorenzo Silva o, incluso, tal vez se vislumbren ecos del Esperan- 
do a Godot de S. Beckett, pues siempre se trata de una espera alumbrada. Los personajes de esta historia buscan en sus vidas un encuentro con lo invisible, pues acceder a lo invisible es percibir símbolos, de modo que lo simbólico es un elemento conductor, una transfiguración visible de contenido espiritual.

\section{Conclusiones}

Lo más interesante de esta perspectiva comparatista es la constatación de que el mito no se restringe a una narración aislada, ni siquiera a los límites de una cultura o época. Así, el mito de la Lamia que impregna estos relatos tiene una coherencia distinta si se examina a la luz de la serie mítica griega que la relaciona con Zeus, Hera, etc., que cuando, más allá de la cosmogonía olímpica, se la considera como un genio local de leyendas de fuentes, donde los hombres son encontrados ahogados o, en todo caso, corren peligro. La tradición gótica y moderna ha distorsionado muchas de estas historias tradicionales en relatos sobre vampiros y otros seres fantásticos. Con ello ha generado una gran cantidad de folclore falsificado cuyo trayecto o continuum es difícil de establecer, pues una historia folclórica de lagos encantados -apenas unos párrafos en las versiones orales antiguasse puede convertir en casi una novela corta, como es el caso de G. Gómez de Avellaneda. Algo similar apreciamos en las recreaciones de estas narrativas míticas de ninfas, en textos como la Égloga III de Garcilaso o en leyendas de Bécquer como Ojos verdes o La cueva de la mora. La relación de atracción-destrucción es más sutil, y la pena o la tristeza se solapan con el estado de felicidad o placidez de estos lugares encantados, donde reside el numen. Las ninfas del Tajo, pese a su felicidad aparente, bordan sus tapices contando tristes historias, igual que deducimos de los relatos becquerianos, donde Eros y Tánatos se enmadejan de forma magistral, y no digamos si nos referimos a la historia de Lorenzo Silva sobre la mujer de Getafe. Lo que cuenta es algo que Eliade (1973) subraya a propósito de la experiencia religiosa: buscar el centro, lo que ordena todo, frente al caos o el desorden. En épocas ancestrales, el lugar de la revelación o del prodigio constituía un recinto sagrado, un témenos, el cual se rodeaba a su vez de un perímetro o cercado, es decir, se contorneaba para separar lo profano y lo sagrado; en 
el caso que nos ocupa, los límites se configuran entre civilización y naturaleza, ciudad y extrarradio, trabajo y placer, privado y social...

Un griego sabía qué espacio era la polis y cuál el oros, y qué se podía esperar. La posmodernidad y sus valores, y la crisis de la sociedad donde se ambienta el relato de Silva, explican la ensoñación inadaptada o la fantasía compulsiva que sufren sus personajes, como ya le pasaba al Fernando de Bécquer. En esencia, es ese mismo estado alterado de conciencia, de duermevela, entre la vigilia y el sueño, y que se opone al sentido común. Frente a tal presión, son personajes que perciben con todos los sentidos, y es su piel o sus ojos los que les permiten descubrir deslumbrantes -o aterradores- interiores, incluyendo secretas correspondencias, que añaden un matiz visionario propio de la intuición simbolista.

En realidad, lo que estos personajes encuentran no es un amor, un objeto de atracción sexual o una alucinación paranoide, serían lecturas demasiado planas. Lo que hallan en el fondo es una especie de oráculo, esto es, la comunicación de una verdad profunda acerca de sus vidas, un espejo que les susurra, o les cuenta o les transmite mediante señales diversas, algo que tiene que ver con el "transeúnte" que camina en busca de un sentido a su viaje, a su mal, a su carencia. Solo desde la más pura banalidad podemos reducir el pozo o la fuente a un lugar taumatúrgico donde se formulan deseos y se echan monedas: es verdad que los poderes del genio acuático arrastran, seducen o encantan a los visitantes, pero son nuestros propios poderes mánticos o adivinatorios los que, al final son invocados, y es nuestra propia capacidad de sanación la que conecta con estos lugares o entidades, sea cual sea su naturaleza.

Ayudan a entender esto visiones omnicomprensivas como la de Calasso (2004): así, las ninfas no son duendes juguetones o simples, al contrario, poseen una naturaleza compleja que, en todo caso, se sitúan al otro lado, al borde de nuestro entorno, es decir, hacen cosas diametralmente distintas a las nuestras: danzar, lavar madejas de oro o vivir en palacios suntuosos a los que se accede por el agua o por otros umbrales, piedras, cuevas o las denominadas casas de hadas. La ambigüedad de Bécquer y el nihilismo casi resignado de Silva no pueden hacernos perder de vista lo más esencial: son los imaginarios personales y colectivos los que dibujan tales contornos y nadie debería minusvalorar el poder de unos “ojos verdes”, es decir, de cualquier imán que ayude a cambiar nuestras vidas, a asomarnos al pozo de 
nuestra conciencia. Pues asomarse al pozo, a la sima, a la orilla es siempre un acto de pisar el umbral, el borde entre dos mundos, y el pozo siempre está relacionado con los mitos mayéuticos o de alumbramiento.

La forma en que Perseo vence a Medusa es también una especie de agon o competición de luces, pues él emplea la coraza, el reflejo, el espejo al fin y al cabo, para anular su poder mortífero, dicho de otro modo, la controla. Por eso también los ojos de la Medusa son como el rayo de Zeus, una llamarada mortal, un rapto, un golpe que sobrecoge, paraliza, inmoviliza, es decir, una plaga en su sentido etimológico de algo que "golpea", que se desata bruscamente, y eso tiene que ver con esa experiencia de flechazo o rapto súbito. Invocar al genio del pozo debería suponer conocer estas reglas del juego: por ejemplo, los malos deseos de los padres acarrean encantamientos para sus hijos. Más allá de toda esta escenografía, los lugares de poder son, a fin de cuentas, un lugar de diálogo de las generaciones, es como si los ancestros estuvieran hablando a sus hijos: las hadas no serían, pues, sino la huella que persiste de esos ancestros, de los manes (Cabal, 1972), en suma, el hilo ininterrumpido de la memoria, aún en estado latente, según expresión del maestro Menéndez Pidal (1934).

En cuanto a la asociación de la mujer con el agua, pensemos en el inmenso bagaje cultural que subyace a este hecho. Relacionar la mujer y la Naturaleza es adentrarse en una red de símbolos, a menudo degradados o caricaturizados, tal como puede colegirse a partir de la monstruosa y mágica Medusa, y otras representaciones femeninas (v.gr. Medea), degradadas ya desde los mitos de los dioses olímpicos. Medusa acabó siendo usada como un amuleto apotropaico y una fuente de poder, así que se puede hacer una lectura "gótico-terrorífica", pero hoy es más relevante la lectura alternativa de que Medusa (tanto como la Dama de la Fuente de los Álamos o el hombre de Getafe de Lorenzo Silva) son una fuente de trascendencia, el genio ancestral que cuida el lugar, el tesoro, y que guarda secretos como la eterna juventud. En esa medida, justamente, es en la que puede servirnos para comprender nuestras propias crisis, la personal, la social o la ambiental. Aun cuando eso, como en el relato de Lorenzo Silva, no se resuelva sino mediante la autodestrucción, al más puro estilo de la novela negra.

En cualquier caso, el hechizo o trance extático no se produce aquí entre Ulises y Calipso, sino entre Fernando y la dama de la fuente, o entre la ejecutiva y el hombre de Getafe. En La Odisea la constelación de mitos 
(Cencillo, 1971: 65) lleva, por ejemplo, a interrelacionar los conceptos de muerte, olvido y sueño (Aguirre Castro, 1998: 10): así, tras el episodio de Calipso, vemos sin duda el papel de la cueva iniciática, al igual que eran muy importantes los ritos de incubación. En efecto, en el santuario citado de Oropo en honor de Anfiarao, si alguien dormía junto al templo del dios o a las tumbas de los antepasados era para recibir sus oráculos.

Así que si se duerme para comunicarse con el dios y recibir sus mensajes, este soñar despierto de Fernando o de la ejecutiva es quizás una forma similar, aunque compulsiva, de este mismo rito ancestral, que impregna los tres casos analizados. Al fin y al cabo, según Eliade (1973), un mito es un modelo ejemplar que hay que repetir, de ahí la pervivencia y actualidad de historias como las glosadas. La ambivalencia de estas damas de agua estaba ya en el folclore, pero adquiere matices románticos o posmodernos al tenor de la estética y la cosmovisión examinadas.

\section{Referencias}

Aguirre Castro, M. (1998). Los peligros del mar: Muerte y olvido en La Odisea. CFC EGI, 8, 10-20.

Ayala Aracil, M. A. (2006). Amor y erotismo en La ondina del lago azul de Gertrudis Gómez de Avellaneda. Romanticismo 9, Actas del IX Congreso. El eros romántico, Bologna, Il Capitello del Solle, 13-23.

Bajtin, M. (1974). La cultura popular en la Edad Media y el Renacimiento. El contexto de François Rabelais. Barcelona: Barral Editores.

Berque, A. (2009). El pensamiento paisajero. Madrid: Biblioteca Nueva.

Cabal, C. (1972). Del folklore de Asturias. Cuentos, leyendas y tradiciones. La mitología asturiana. Oviedo: I.D.E.A.

Calasso, R. (2004). La locura que viene de las ninfas y otros ensayos. México: Sexto Piso. Versión de 1992 publicada en Revista de Estudios Políticos de la UNAM, 12, 257-275.

Caparrós Esperante, L. (1991). Rimas. Ed. de Russell P. Sebold. Madrid: Espasa Calpe (Clásicos Castellanos, Nueva Serie, 22).

Charques Gámez, R. (2013). Lo culto y lo popular en las tradiciones vascas y pirenaicas de Gertrudis Gómez de Avellaneda. En Thion-Soriano, D.; Beltrán Almería, L.; Hibbs-Lissorgues, S. y Sotelo Vázquez, M. (coords.), Tradición e interculturalidad: las relaciones entre lo culto y lo popular (siglos XIX$X X)$ (pp. 69-79). Zaragoza: IFC.

Cencillo, L. (1971). Mito: semántica y realidad. Madrid: Editorial B.A.C. 
Dumézil, G. (1977). Mito y epopeya. Barcelona: Seix Barral.

Eliade, M. (1973). Mito y realidad, Madrid: Editorial Guadarrama.

Flys Junquera, C.; Marrero Henríquez, J. M. y Barella Vigal, J. (eds.) (2010). Ecocríticas. Madrid: Iberoamericana.

Genette, G. (1989). Palimpsestes.La littérature au second degré. Paris: Seuil.

Gimbutas, M. (1974). Diosas y dioses de la vieja Europa. 700o-350o a. C. Madrid: Colegio Universitario de Ediciones Istmo.

Gimbutas, M. (1996). El lenguaje de la diosa. Oviedo: Dove.

Gómez de Avellaneda, G. (1974). Obras completas. Madrid: Ediciones Atlas.

Graves, R. (1983 [1948]). La Diosa Blanca. Madrid: Alianza Editorial.

Guimaraes, A. P. (2004). Falas da Terra - Natureza e Ambiente na tradição popular portuguesa. Lisboa: Colibrí.

Gulsoy, J. (1967). La fuente común de "Los ojos verdes" y "El rayo de Luna". Bulletin of Hispanic studies, 44, 2, 96-106.

Harrison, J. E. (1903). The Ker as Gorgon. Prolegomena to the study of the Greek religion. Cambridge: Harvard University Press.

Lotman, I. (1979). Semiótica de la cultura. Madrid: Cátedra.

Martín Gaite, C. (2013). Caperucita en Manhattan. Madrid: Siruela.

Martos Núñez, E. y Martos García, A. (2011). Memorias y mitos del agua en la Península Ibérica. Barcelona: Marcial Pons. Ediciones Jurídicas y Sociales.

Menéndez Pidal, R. (1934). Historia y epopeya. Madrid: Centro de Estudios Históricos.

Otto, R. (1980). Lo santo. Lo racional y lo irracional en la idea de Dios. Madrid: Alianza Editorial.

Scavino, L. y Buzón, R. (2008). Traducción y transtextualidad en "La casa de Asterión” de J. L. Borges: una poética de la polifonía. Espéculo. Revista de estudios literarios, 38. Disponible en http://pendientedemigracion.ucm. es/info/especulo/numero38/asterion.html

Silva, L. (ed.). (2007). Leyendas de Bécquer. Madrid: Ediciones 451.

Vax, L. (1960). Literatura y arte fantástica. Buenos Aires: Eudeba. 